\title{
Uso das plantas medicinais para fins terapêuticos por estudantes do Ensino Médio
}

\author{
Use of medicinal plants for therapeutic purposes by High School students \\ Uso de plantas medicinales con fines terapéuticos por parte de Estudiantes de Secundaria
}

Nayara Duarte de Andrade
ORCID: https://orcid.org/0000-0002-8558-7554
Instituto Federal de Educação, Ciência e Tecnologia do Maranhão, Brasil
E-mail: Nayaraduarte475@gmail.com
Breno Machado de Almeida
ORCID: https://orcid.org/0000-0003-0982-8886
Universidade Federal de Viçosa, Brasil
E-mail: breno.m.almeida@ufv.br
Regina Maria Silva Sousa
ORCID: https://orcid.org/0000-0002-6300-0361
Universidade Federal do Piauí, Brasil
E-mail: reginasousa484@gmail.com
Maurício dos Santos Araújo
ORCID: https://orcid.org/0000-0002-7728-2590
Universidade Federal de Viçosa, Brasil
E-mail: mauricio.araujo@ufv.br

\begin{abstract}
Resumo
As plantas medicinais são usadas como recurso alimentar e terapêutico pelas civilizações ao longo da história da humanidade. Entretanto, o conhecimento ao nível biológico é pouco discutido em sala de aula. Sendo assim, o objetivo do estudo foi realizar o levantamento dos conhecimentos dos estudantes do Ensino Médio sobre o uso das plantas medicinais para fins terapêuticos em uma escola pública do estado do Piauí. Dessa forma, os dados foram coletados por formulário eletrônico e aplicado com 33 alunos do Ensino Médio da rede pública de ensino no Estado do Piauí. Em seguida, os dados foram submetidos a análise estatística descritiva de frequência e categorias analíticas para os dados qualitativos. Os alunos citaram 17 exemplares de plantas, onde o chá e as folhas foram as principais formas de uso e preparo, respectivamente. As plantas eram usadas, principalmente no tratamento de problemas respiratórios e gastrointestinais, sendo que, os exemplares mais citados foram hortelã e erva-cidreira. Observou-se ainda que, os alunos tinham conhecimento fragmentado sobre as finalidades terapêuticas das plantas medicinais e os possíveis danos causados ao material genético. As plantas por serem um recurso natural, os alunos acreditavam que não causavam danos ao organismo. Assim, verifica-se que o conhecimento tradicional sobre as plantas medicinais está presente na vida dos alunos, apesar do pouco conhecimento científico associado.
\end{abstract}

Palavras-chave: Ensino; Botânica; Conhecimento popular; Ensino de Biologia.

\begin{abstract}
Medicinal plants are used as a food and therapeutic resource by civilizations throughout human history. However, knowledge at the biological level is rarely discussed in the classroom. Thus, the study aimed to survey the knowledge of high school students about the use of medicinal plants for therapeutic purposes in a public school in the state of Piauí. Thus, data were collected by electronic form and applied to $33 \mathrm{high}$ school students from public schools in the state of Piauí. Then, the data were subjected to descriptive statistical analysis of frequency and analytical categories for qualitative data. The students cited 17 specimens of plants, where tea and leaves were the main forms of use and preparation, respectively. The plants were used, mainly in the treatment of respiratory and gastrointestinal problems, and the most cited specimens were mint and lemon balm. It was also observed that the students had fragmented knowledge about medicinal plants' therapeutic purposes and the possible damages caused to the genetic material. As plants are a natural resource, students believed that they did not cause damage to the organism. Thus, it appears that traditional knowledge about medicinal plants is present in the lives of students, despite the little associated scientific knowledge.
\end{abstract}

Keywords: Teaching; Botany; Popular knowledge; Biology teaching.

\section{Resumen}

Las plantas medicinales son utilizadas como alimento y recurso terapéutico por las civilizaciones a lo largo de la historia de la humanidad. Sin embargo, el conocimiento a nivel biológico rara vez se discute en el aula. Así, el estudio 
tuvo como objetivo aumentar el conocimiento de los estudiantes de secundaria sobre el uso de plantas medicinales con fines terapéuticos en una escuela pública del estado de Piauí. Así, los datos fueron recolectados electrónicamente y aplicados a 33 estudiantes de secundaria de escuelas públicas del estado de Piauí. Luego, los datos fueron sometidos a análisis estadístico descriptivo de frecuencia y categorías analíticas para datos cualitativos. Los estudiantes citaron 17 ejemplares de plantas, siendo el té y las hojas las principales formas de uso y preparación, respectivamente. Las plantas se utilizaron principalmente en el tratamiento de problemas respiratorios y gastrointestinales, siendo los ejemplares más citados la menta y el melisa. También se observó que los estudiantes tienen conocimiento fragmentado sobre los propósitos terapéuticos de las plantas medicinales y el posible daño causado al material genético. Debido a que las plantas son un recurso natural, los estudiantes creen que no causan daño al organismo. Así, parece que el conocimiento tradicional sobre plantas medicinales está presente en la vida de los estudiantes, a pesar del escaso conocimiento científico asociado.

Palabras clave: Ensenãnza; Botánica; Conocimiento popular; Enseñanza de la biología.

\section{Introdução}

O homem sempre buscou na natureza recursos genéticos vegetais para sua alimentação, vestimentas, sobrevivência e meios curativos (Dantas \& Torres, 2019). A utilização das plantas medicinais é anterior ao surgimento da agricultura, há cerca de 40 mil anos, povos neandertais (Homo neanderthalensis) já faziam uso no tratamento de enfermidades ou medidas curativas (Weyrich, et al., 2017). Com o avanço científico foi possível progredir nos estudos toxicológicos, a fim de promover segurança no consumo de substâncias a base desses vegetais (Salesse, et al., 2018).

A etnobotânica e a etnofarmacologia são áreas responsáveis por resgatar e valorizar os saberes tradicionais da população e suas aplicações científicas e tecnológicas no uso correto e sustentável dos recursos vegetais (Sales, et al., 2015). Estudos etnobotânicos permitem conhecer a interação entre o homem e a natureza, e as possíveis aplicações das plantas medicinais na medicina popular (David \& Pasa, 2017). Já a etnofarmacologia contribui para a descoberta de novos compostos fitoquímicos com ações farmacológicas, fornecendo dados importantes a respeito da segurança na utilização de medicamentos extraídos da flora nativa e invasora (Pio, et al., 2018).

O conhecimento das plantas medicinais é amplo e a escola tem um papel importante na valorização dos saberes dos alunos, que foram construídos ao longo das vivências sociais (Araújo \& Lima, 2019). O ensino de Botânica teve grandes avanços nos últimos anos, mas ainda requer inovações para a construção da aprendizagem (Lima, et al., 2019). O entendimento desses saberes possibilita o intercâmbio entre diversas áreas do conhecimento científico (Santos \& Macedo, 2017). Desse modo, essas abordagens promovem uma aprendizagem integradora para que o aluno participe ativamente do processo de ensino-aprendizagem (Silva \& Santos, 2017).

\section{Conhecimento etnobotânico e etnofarmacológico}

As plantas medicinais são vegetais com ações farmacológicas que possuem efeito de tratar e amenizar algumas enfermidades (Mera, et al., 2018). O termo Etnobotânica foi descrito no ano de 1985, pelo botânico Jonh William Hasherberg, como área do conhecimento que estuda as plantas medicinais e a sua relação com o ser humano (Silva, 2017). Esses conhecimentos são pautados na valorização dos saberes tradicionais e uso dos recursos naturais de forma sustentável (Oliveira, et al., 2020a). A relação promovida pela etnobotânica já existe a milhares de anos, o que indica a forte dependência ao longo das gerações (Lima \& Oliveira, 2020). Por outro lado, a etnofarmacologia busca avaliar e validar cientificamente o conhecimento empírico acerca de preparações medicinais em determinados grupos étnicos ou sociais, relacionando a sistemas tradicionais de medicina (Santos \& Pinheiro, 2016).

O uso e conhecimento acerca de plantas medicinais atravessam séculos, desde os primórdios da humanidade até os dias atuais (Cavalcanti, et al., 2020). Diante dessa prática, as pessoas buscam na flora nativa espécies com finalidades 
terapêuticas (Zardo, et al., 2016). Nas últimas décadas, vem ocorrendo uma crescente procura pelas terapias alternativas e produtos naturais. No Brasil, muitos estudos toxicológicos têm buscado a comprovação das atividades biológicas das plantas medicinais. A avaliação desses recursos busca quantificar e qualificar as substâncias presentes na planta, e verificar a toxicidade nos organismos vivos (Oliveira, et al., 2020b).

No final da década de 1970, foi criado pela Organização Mundial de Saúde (OMS) o Programa de Medicina Tradicional (PMT) com o objetivo de promover o uso racional das plantas medicinais. Entre as finalidades práticas, buscava-se a promoção de políticas públicas para unir a medicina convencional e os métodos terapêuticos tradicionais (Sales, et al., 2015). O Programa Nacional de Plantas Medicinais e Fitoterápicos (PNPMF) busca promover e reconhecer as práticas tradicionais de uso de plantas medicinais, fitoterápicos e remédios caseiros pela população (Zeni, et al., 2017). Nos últimos anos, o governo federal brasileiro tem colocado em prática políticas públicas para implementação do uso de fitoterápicos na rede pública de saúde como alternativa terapêutica (Salesseet, et al., 2018).

\section{Conhecimento tradicional associado ao ensino de botânica}

O conhecimento popular possibilita ao professor a capacidade de conhecer o meio em que o aluno vive (Lima \& Oliveira, 2020). Saberes dessa natureza permitem o estudo do ambiente e conservação da natureza, levando em conta a diversidade cultural que envolve as comunidades humanas (David \& Pasa, 2017). O ensino de Ciências/Biologia é importante na valorização e resgate dos conhecimentos empíricos dos alunos, tais ações promovem a valorização das suas experiências extraescolar (Kovalski, 2013).

A etnobotânica no ambiente escolar surge como instrumento promissor para o ensino de Ciências/Biologia. Essa área permite o resgate da cultura popular e a expressão do conhecimento dos alunos sobre plantas (Santos \& Campos, 2019). A valorização do conhecimento local no ambiente escolar permite a integração entre saberes científicos e populares (Costa \& Pereira, 2016). No entanto, a abordagem etnobotânica ainda é primária no ensino de Botânica (Ursi, et al., 2018), onde ambientes como os jardins botânicos são considerados verdadeiros laboratórios naturais. Esses locais podem ser utilizados como recursos didáticos para o ensino da morfologia, ecologia, e uso das espécies vegetais, assim como, o conhecimento tradicional local associado à biodiversidade (Lazarri, et al., 2017). Ao trabalhar a Botânica em sala de aula é possível abordar sobre a importância dos conhecimentos de comunidades tradicionais, possibilitando a investigação sobre as principais propriedades biológicas das plantas (Ferreira, et al., 2017).

As plantas medicinais podem ser ferramentas motivadoras no ensino de Biologia, uma vez que, vários aspectos podem ser abordados em conteúdos de botânica, tais como, nomenclatura, componentes químicos e estruturais, metabólitos primários e secundários, características evolutivas e ciclo da planta (Silva \& Santos, 2017). Apesar disso, o ensino de botânica ainda é descontextualizado em sala de aula devido, às vezes, o livro didático ser a única forma de utilização, tornando assim, essa prática de ensino distante da realidade dos alunos (Costa, et al., 2019). Contudo, os estudantes precisam compreender a importância do ensino de botânica, o seu processo evolutivo, formas de reprodução, ressaltando a importância das plantas para todos os seres vivos que compreendem o ecossistema (Barbosa, et al., 2020).

Existe uma escassez de estudos que versam sobre conhecimento etnobotânico e etnofarmacológico no âmbito educacional, havendo apenas pesquisas mais direcionadas ao levantamento das espécies usadas por moradores em comunidades rurais (Santos, et al., 2016). Abordagens dessa natureza, precisam ser intensificadas, a fim de promover informações sobre os benefícios e malefícios das plantas medicinais. Assim como, a valorização do conhecimento tradicional e aproximação do aluno aos saberes científicos (Madeiro \& Lima, 2015). Portanto, o objetivo do estudo foi realizar o levantamento dos conhecimentos de estudantes do Ensino Médio sobre o uso das plantas medicinais para fins terapêuticos em 
uma escola pública do estado do Piauí.

\section{Metodologia}

O estudo foi conduzido no município de Canavieira (latitude $07^{\circ} 41^{\prime} 17^{\prime \prime} \mathrm{S}$, longitude $43^{\circ} 43^{\prime} 14^{\prime \prime} \mathrm{O}$ e $180 \mathrm{~m}$ de altitude), localizado no interior do estado do Piauí, Brasil (IBGE, 2010). A pesquisa foi do tipo levantamento (Survey) usada para a identificação dos conhecimentos sobre o uso das plantas medicinais pelos alunos da Educação Básica. A abordagem foi do tipo qualitativa e quantitativa, com enfoque na descrição das falas dos pesquisados sobre a temática avaliada. Segundo Ferreira et al. (2020), a abordagem mista na área da educação proporciona ganhos no meio científico, devido à ampliação de ferramentas analíticas e estratégias de interpretação durante a condução do estudo.

O estudo foi desenvolvido em uma escola da rede pública de ensino do município, onde trinta e três alunos da $3^{a}$ série do Ensino Médio participaram da pesquisa. Todos os alunos aceitaram os termos de condução do estudo, por isso, usou-se códigos de $\mathrm{A}_{1}, \mathrm{~A}_{2}, \mathrm{~A}_{3}, \ldots, \mathrm{A}_{33}$, de modo a preservar a identidade dos participantes. $\mathrm{O}$ Termo de Consentimento e Livre Esclarecimento (TCLE) foi assinado pelos alunos maiores de 18 anos, e com autorização do responsável para aqueles menores de idade, seguindo a resolução 510/2016 (Brasil, 2016).

Os dados foram coletados por meio de formulário eletrônico/questionário construído na plataforma Google forms. O formulário foi enviado para todos os alunos via e-mail, no qual esse foi disponibilizado pela escola de modo a facilitar o contato com eles. Já para os alunos que não tinham acesso à internet foi entregue o questionário físico, seguindo todas as recomendações de proteção estabelecida pela Organização Mundial da Saúde devido à pandemia da COVID-19. As questões abordavam assuntos relacionados a: a) caracterização sociodemográfica e socioeconômica; b) uso das plantas medicinais para fins terapêuticos; c) categoria de planta usada no tratamento de alguma doença; d) forma de preparo; e) local de aquisição de espécime vegetal; f) finalidade terapêutica na perspectiva do aluno; g) conhecimento sobre as plantas medicinais; h) danos causados pelas plantas no material genético; e i) uso de tecnologias associadas ao tratamento correto dos recursos vegetais. $\mathrm{O}$ instrumento de coleta de dados foi empregado devido a ampla agilidade, praticidade e sustentabilidade (Andres, et al., 2020). O conhecimento tradicional associado as plantas medicinais usada pelos alunos seguiram a metodologia proposta por Mera et al. (2018) e Araújo e Lima (2019), onde os alunos identificaram os exemplares por meio da avaliação de imagens disponibilizadas seguindo a classificação do Grupo de Filogenia das Angiospérmicas (Cronquist, 1988)

Os dados qualitativos foram interpretados pela abordagem proposta por Griffin et al. (2003), Carneiro e Silva (2007) e Araújo e Lima (2019) com adaptações na descrição das categorias de análise. A avaliação foi feita com base na submissão das respostas a luz da análise de categorias. As falas dos alunos foram interpretadas com base no nível de compreensão sobre o problema questionado (Quadro 1). 
Quadro 1. Categoria de análise dos dados qualitativos sobre conhecimento etnobotânico e uso das plantas medicinais por alunos do Ensino Médio

\begin{tabular}{|c|c|c|}
\hline \multicolumn{3}{|c|}{ Análise Qualitativa } \\
\hline Categoria & Tipo de resposta & Avaliação do conhecimento do aluno \\
\hline 0 & Sem resposta & $\begin{array}{l}\text { O aluno não respondia, ou respondia, como por exemplo, "não } \\
\text { sei" ou "não conheço", além de contextualizar a questão de } \\
\text { forma errada. }\end{array}$ \\
\hline I & Pobre/sem informação & $\begin{array}{l}\text { Falta de compreensão sobre o tema ou respostas sem conexões } \\
\text { com o problema. }\end{array}$ \\
\hline II & $\begin{array}{l}\text { Fraca e falta de conexões entre os } \\
\text { conceitos }\end{array}$ & $\begin{array}{l}\text { Manifesta a compreensão básica dos conceitos, mas sem } \\
\text { fundamentação teórica ou conexão com os saberes científicos. }\end{array}$ \\
\hline III & $\begin{array}{l}\text { Satisfatória/racional e estabelece } \\
\text { conexões entre os conceitos }\end{array}$ & $\begin{array}{l}\text { Demonstra a compreensão dos elementos científicos mais } \\
\text { importantes sobre o problema }\end{array}$ \\
\hline IV & $\begin{array}{l}\text { Excelente/racional e estabelece } \\
\text { conexões dos conceitos e aplicações em } \\
\text { outras áreas do conhecimento }\end{array}$ & $\begin{array}{l}\text { Percebe-se a compreensão holística sobre o tema, com } \\
\text { refinamento nas respostas, discussões além do que foi } \\
\text { questionado. O aluno demonstra o domínio do conteúdo e a } \\
\text { capacidade sistemática em aplicar esses saberes. }\end{array}$ \\
\hline
\end{tabular}

Fonte: Autores (2020).

Todos os sintomas das doenças relatados no tratamento foram categorizados pelo International Statistical Classification of Diseases and Related Health Problems (ICD). A ICD classifica as doenças/sintomas em: doenças infecciosas e parasitárias (DIP); sistema digestório (SD); sistema reprodutor feminino (SRF); sistema nervoso (SN); sistema cardiovascular (SC); sintomas não classificados (SNC); sistema endócrino (SE); doença de pele (DP); ossos e cartilagens articulares (OC); doenças do aparelho geniturinário (DAG) (WHO, 1992). Os dados quantitativos foram submetidos a análise descritiva de frequência e correlação de Spearman (Rs), adotando $p<0,05$ como nível de confiança. Todas as análises foram feitas no software Statistical Package for the Social Sciences (SPSS) 26.0.

\section{Resultados e Discussão}

A investigação mostrou que $36,4 \%$ dos alunos eram do sexo masculino e $63,6 \%$ do sexo feminino. A faixa etária média foi de $18 \pm 0,89$ anos e 51,5\% residiam na zona rural e 48,5\% na zona urbana do município de Canavieira - Piauí. A renda familiar bruta predominante foi até um salário mínimo (Tabela 1). O sexo dos alunos mostrou uma correlação significativa com três variáveis: idade $\left(0,859^{* *} ; p<0,01\right)$, local onde residem $(0,779 * * ; p<0,01)$, informações sobre plantas medicinais $(0,764 * * 8 ; p<0,01)$. Já a idade teve duas correlações significativas: a renda bruta familiar $(0,725 * * ; p<0,01)$ e com as informações sobre plantas medicinais $(0,783 * * ; p<0,01)$. 
Tabela 1. Caracterização dos alunos quanto as variáveis sexo, idade, local onde residem, renda familiar bruta.

\begin{tabular}{|c|c|c|}
\hline Variável & $\mathbf{F}^{*}$ & $\%$ \\
\hline \multicolumn{3}{|l|}{ Sexo } \\
\hline Masculino & 12 & 36,40 \\
\hline Feminino & 21 & 63,60 \\
\hline \multicolumn{3}{|l|}{ Idade } \\
\hline 14-15 anos & 11 & 33,30 \\
\hline 16-17 anos & 9 & 27,30 \\
\hline 18-19 anos & 13 & 39,40 \\
\hline \multicolumn{3}{|l|}{ Onde reside } \\
\hline Zona urbana & 16 & 48,50 \\
\hline Zona rural & 17 & 51,50 \\
\hline \multicolumn{3}{|l|}{ Renda familiar bruta } \\
\hline Até R\$1.045,00 & 23 & 69,70 \\
\hline $\mathrm{R} \$ 1.045,00$ a $\mathrm{R} \$ 2.090,00$ & 6 & 18,20 \\
\hline $\mathrm{R} \$ 2.090,00$ a $\mathrm{R} \$ 3.135,00$ & 2 & 6,10 \\
\hline $\mathrm{R} \$ 3.280,00$ a $\mathrm{R} \$ 4.325,00$ & 2 & 6,10 \\
\hline
\end{tabular}

Fonte: Autores (2020).

A crescente busca por métodos alternativos e curativos vêm sendo observada ao longo dos anos. O emprego de plantas medicinais com fins terapêuticos é evidente devido à eficácia nos tratamentos e por ser de baixo custo. Essa prática é constante, principalmente pela população mais carente que, às vezes, não tem acesso à medicina moderna (Neri, et al., 2018). As plantas medicinais ainda são consideradas por muitas pessoas como um recurso inofensivo por ser natural (Zeni, et al., 2017). Devido ao fácil acesso e a prática que perdura durante às gerações, muitos alunos consideram um tratamento terapêutico inofensivo, onde chegam, às vezes, a substituir um fármaco por uma planta medicinal (Araújo \& Lima, 2019).

Os alunos citaram 17 exemplares que são usados por eles ou familiares. A principal forma de preparo foi o chá, seguido por lambedor e decocção. A obtenção desses espécimes ocorre em jardins das próprias residências e na mata (floresta situada ao redor das residências). Em relação as estruturas vegetais mais utilizadas nas preparações dos produtos medicinais, observou-se maior frequência de folhas, seguido da casca, raiz e semente e o menos citado foi o fruto. Quando questionados sobre as finalidades terapêuticas, o tratamento de gripe, problemas respiratórios e doenças gastrointestinais foram os mais citados e dentre as plantas, a hortelã e a erva-cidreira ganharam maior destaque, ambas utilizadas para tratar febre e gripe (Tabela 2). 
Tabela 2. Plantas medicinais citadas pelos alunos com seu nome popular, forma de preparo, estrutura usada, onde adquiriu e sua finalidade terapêutica na perspectiva dos alunos.

\begin{tabular}{lllllll}
\hline NP* & FP & EU & LA & F & $\%$ & FT \\
\hline Erva-cidreira & Chá & Folha & Quintal & 6 & 15,38 & DIP e SNC \\
Boldo & Chá & Folha & Quintal & 4 & 10,25 & SD e SE \\
Malva do reino & Lambedor & Planta inteira & Horta e Quintal & 2 & 5,12 & DIP \\
Hortelã & Chá & Folha & Quintal & 10 & 25,64 & DIP \\
Gengibre & Chá & Raiz & Feiras livres & 3 & 7,69 & DIP \\
Trevo & Chá & Folha & Quintal & 1 & 2,56 & SC \\
Laranja & Chá & Casca & Quintal & 2 & 5,12 & SD \\
Alecrim & Lambedor & Folha & Quintal & 1 & 2,56 & DIP e SE \\
Babosa & Lambedor & Folha & Quintal & 1 & 2,56 & SNC \\
Velame & Lambedor & Folha & Mata & 2 & 5,12 & DIP \\
Erva doce & Chá & Semente & Feiras livres & 1 & 2,56 & SNC \\
Avelã & Chá & Fruto & Mata & 1 & 2,56 & SE \\
Limão & Chá & Casca & Quintal & 1 & 2,56 & DIP \\
Catinga de porco & Chá & Casca & Mata & 1 & 2,56 & SD \\
Mastruz & Decocção & Folha & Mata & 1 & 2,56 & SD, SE e SNC \\
Imburana & Chá & Sementes & Mata & 1 & 2,56 & SD \\
Cansanção & Chá & Raiz & Mata & 1 & 2,56 & OC \\
\hline
\end{tabular}

${ }^{*} \mathrm{NP}=$ nome popular, $\mathrm{FP}=$ forma de preparo, $\mathrm{EU}=$ estrutura utilizada, $\mathrm{LA}=$ local de aquisição, $\mathrm{FT}=$ finalidade terapêutica Fonte: Autores (2020).

Em um estudo realizado no Parque Nacional Serra da Capivara - PI (Reis, et al., 2017), e em duas escolas públicas do Maciço de Baturité - CE, o chá foi apontado como a forma de preparo mais utilizado pelos alunos (Xavier, et al., 2019). Isso pode ser explicado pelo fato de o chá ser a segunda bebida mais consumida no mundo (Costa \& Marinho, 2016). Em outro levantamento realizado com os estudantes do curso de farmácia em Montes Claros - MG, apontou que as plantas medicinais são adquiridas pela maioria dos acadêmicos no quintal de casa $(45,5 \%)$, mercado (12,9\%) e nos quintais das residências vizinhas (10,6\%) (Santos, et al., 2017).

Em estudo realizado em Buriticupu - MA, as folhas também foram as mais citadas (Colacio, et al., 2019). No entanto, outro estudo desenvolvido na Serra da Capivara - PI, observou-se um resultado diferente, no qual a parte mais utilizada foi a casca, geralmente empregada para preparação de chás e banhos (Reis, et al., 2017). O uso da folha é de fácil acesso e manipulação, além de promover a conservação do recurso vegetal, pois não impede o desenvolvimento e a reprodução da planta, caso a retirada área não seja excessiva (Belizário \& Silva, 2012). Diversas publicações apontam que as folhas é a estrutura vegetal mais explorada na medicina popular. Apesar disso, as folhas nem sempre concentram a maior quantidade de princípios ativos, porém a aquisição é de maior facilidade (Cajaíba, et al., 2016).

Em um estudo similar foi observado que as plantas medicinais são utilizadas em problemas do sistema digestório, respiratório, geniturinário, sistema nervoso, sistema circulatório, doenças da pele e lesões cutâneas (Reis, et al., 2017). Resultados semelhantes foram encontrados em um trabalho realizado na comunidade da Brenha, Redenção - CE, onde a hortelã foi apontada como a principal planta medicinal e a folha como a mais utilizada no preparo do chá para tratar doenças 
respiratórias. Este fato pode ser atribuído a ampla disponibilidade dessa planta e o cultivo nas próprias moradias (Santos, et al., 2018).

Durante o estudo, verificou-se que, os discentes possuíam conhecimento fragmentado e insuficiente sobre os principais danos que os metabólitos secundários podem causar ao material genético. O entendimento sobre os aspectos botânicos, princípios ativos e ação terapêutica eram desconhecidos pelos alunos. Com base na análise de categorias ficou evidente que, $\mathrm{C} 0$ e $\mathrm{C} 1$ confirmam a hipótese de que, os alunos precisam ampliar seus conhecimentos sobre a temática (Figura 1).

Figura 1. Categorização das respostas dos alunos sobre o entendimento das plantas medicinais e os danos causados no material genético em decorrência do uso das plantas medicinais.

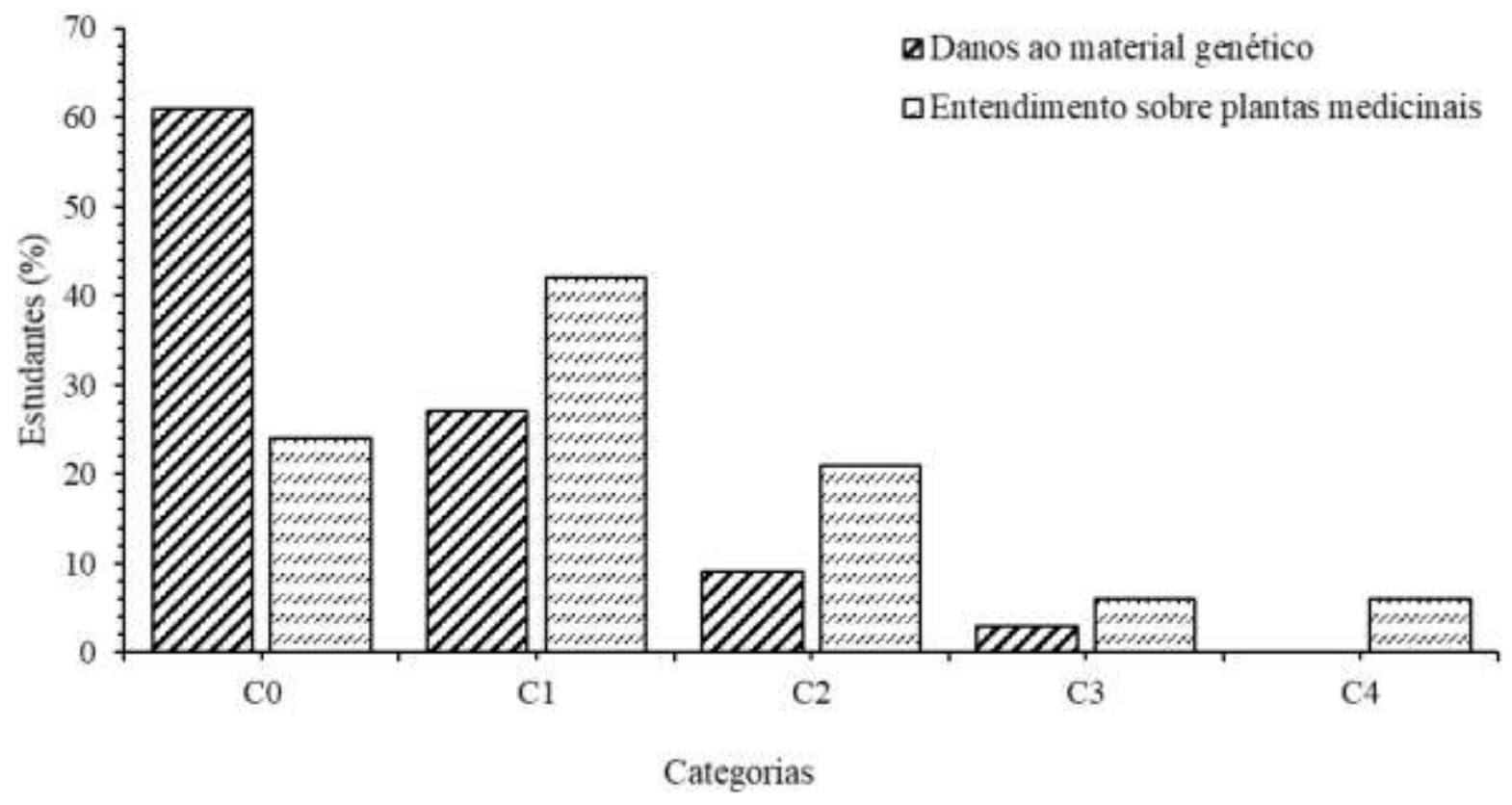

Fonte: Autores.

Em um levantamento sobre os conhecimentos etnobotânicos, $69 \%$ dos alunos da $1^{\text {a }}$ série do ensino médio de uma escola pública de Salvaterra - PA, tinham um entendimento amplo sobre o uso terapêutico das plantas medicinais (Barboza, et al., 2020). Entretanto, Araújo e Lima (2019) demonstraram por meio de categorias analíticas que discentes do Ensino Médio não tem um conhecimento holístico em nível celular, dos principais danos que as plantas podem causar ao material genético. Isso sugere que a temática não é abordada de forma ampla na grade curricular desses estudantes.

Resultado similar foi reportado em duas escolas, pública e privada em Floriano - PI, demostrando que os alunos não tinham conhecimento dos danos que as plantas medicinais poderiam causar ao material genético. No entanto, alguns alunos conseguiram explicar de forma satisfatória e uma pequena porcentagem demonstrou ter conhecimento holístico sobre esses problemas em nível celular (Araújo \& Lima, 2019).

\section{Considerações Finais}

As plantas medicinais estão presentes na vida dos alunos, apesar do emprego frequente, há ainda poucas informações sobre o uso correto. Os estudantes não possuem o conhecimento sobre os riscos que elas podem causar à saúde humana devido 
ao uso inadequado. Portanto, estudos que estimulem a valorização dos saberes extraescolar dos alunos são de grande relevância para a construção dos saberes científicos em Biologia. Devido ao ensino da Botânica ser abordado quase que exclusivamente de forma teórica e descontextualizada, pode-se ainda sugerir com o presente trabalho, a elaboração de uma sequência didática de atividades laboratoriais sobre plantas medicinais em parceria com instituições de Ensino Superior, bem como a criação de um aplicativo para smartphones que identifique e descreva brevemente as espécies vegetais, passando a ser mais uma alternativa na busca de informações acerca do uso discriminado das plantas medicinais.

\section{Agradecimentos}

Ao Instituto Federal de Educação, Ciência e Tecnologia do Maranhão (IFMA) e ao programa de Pós-Graduação em Informática na Educação.

\section{Referências}

Andres, F. C., Andrade, S. C., Moreschi, C., Rodrigues, S. O. \& Ferst, M. F. (2020). A utilização da plataforma Google forms em pesquisa acadêmica: relato de experiência. Research, Society and Development, 9(9), 1-7.

Araújo, M. S. \& Lima, M. M. O. (2019). O uso de plantas medicinais para fins terapêuticos: os conhecimentos etnobotânicos de alunos de escolas públicas e privada em Floriano, Piauí, Brasil. Amazônia: Revista de Educação em Ciências e Matemática, 15 (33), $235-250$.

Barboza, A. C., Amador, M. S. M., Gomes, P. W. P., Brito, J. S., Miranda, T. G., Martins-Junior, A. S., Pontes, A. N. \& Tavares-Martins, A. C. C. (2020). Percepção dos alunos a respeito do uso de plantas medicinais em escolas públicas de Salvaterra. Biota Amazônia: Open Journal System, 10, 24-30.

Barbosa, M. C. P., Santos, J. W., Silva, F. C. \& Guilherme, B. C. (2020). O ensino de botânica por meio de sequência didática: uma experiência no ensino de ciências com aulas práticas. Brazilian Journal of Development, 6 (7), 45105-45122.

Belizário, T. L. \& Silva, L. A. (2012). Abordagem etnobotânica no tratamento de parasitoses em comércios de fitoterápicos e numa comunidade rural em Uberlândia-MG. Enciclopédia Biosfera, 8 (15), 1730-1739.

Brasil. (2016). Ministério da Saúde. Resolução nº 510, de 07 de abril de 2016. Publicada no DOU no 98, terça-feira, 24 de maio de 2016 , seção 1, 44-46.

Cajaíba, R. L., Cajaiba, R. L. \& Parry, M. M. (2016). Levantamento etnobotânico de plantas medicinais comercializadas no município de Uruará, Pará, Brasil. Revista Biotemas, 29, 115-131.

Cavalcanti, C. A., Andrade, Y. V. S. \& Lima, C. G. (2020). Estudo Etnobotânico sobre a contribuição do uso de plantas medicinais utilizadas no Sítio Frexeira Velha, pertencente ao Município de Pesqueira - PE. Brazilian Journal of Development, 6 (12), 94929-94940.

Carneiro, S. P. \& Silva, J. (2007). O Teste Allium cepa no ensino de biologia celular: um estudo de caso com alunos da graduação. Revista Acta Scientiae, 9 (2), 122-130

Colacio, D. S., Cajaiba, R. L., Sousa, L. A., Martins, J. S. C. \& Sousa, E. S. (2019). Levantamento etnobotânico de plantas medicinais comercializadas no município de Buriticupu. Revista Cubana de Plantas Medicinales, 24 (4), 1-17.

Costa, E. A., Cajaiba, R. L., Sousa, L. A., Martins, J. S. C. \& Sousa, E. S. (2019). Gamificação da botânica: uma Estratégia para a cura da "Cegueira Botânica”. Revista Insignare Scientia, 2 (4), 79-99.

Costa, J. C. \& Marinho, M. G. V. (2016). Etnobotânica de plantas medicinais em duas comunidades do município de Picuí, Paraíba, Brasil. Revista Brasileira de Plantas Medicinais, 18, 125-134.

Costa, S. \& Pereira, C. (2016). Etnobotânica como subsídio para educação ambiental nas aulas de ciências. Revista Brasileira de Educação Ambiental, 11 (2), $279-298$.

Cronquist, A. (1988). The evolution and classification of flowering plants. Bronx: New York Botanical Garden.

Dantas, I. M. J. \& Torres, A. M. (2019). Abordagem etnobotânica de plantas medicinais em uma comunidade rural do sertão Alagoano. Diversitas Journal, 4, 39-48.

David, M. \& Pasa, M. C. (2017). Articulações entre a etnobotânica e os conhecimentos da disciplina ciências da natureza. Rede Amazônica de Educação em Ciências e Matemática, 5 (2), 249-264.

Ferreira, M., Barbieri, J. F., Almeida, J. J. G. \& Winckler, C. (2020). Introdução e condução dos métodos mistos de pesquisa em educação física. Pensar a Prática, 23, e59905.

Ferreira, G., Campos, M. D. G. P. A., Pereira, B. L. \& Santos, G. B. (2017). A etnobotânica e o ensino de botânica do ensino fundamental: possibilidades metodológicas para uma prática contextualizada. Flovet, 1 (9), 86-101. 
Griffin, V., McMiller, T., Jones, E. \& Johnson, C. M. (2003). Identifying novel helix-loophelix genes in Caenorhabditis elegans through a classroom demonstration of functional genomics. Cell Biology Education, 2, 51- 62.

Ibge. Instituto Brasileiro de Geografia e Estatística. (2010). Organização do território, estrutura territorial, localidades. Brasília, DF, 2010. https://geoftp.ibge.gov.br/organizacaodo_territorio/estrutura_territorial/localidades/Geomedia_MDB.

Kovalski, M. L. \& Obara, A. T. (2013). O estudo da etnobotânica das plantas medicinais na escola. Ciência \& Educação, 19 (4), $911-927$.

Lazarri, G., Gonzatti, F., Scopel, J. M. \& Scur, L. (2017). Trilha ecológica: um recurso pedagógico no ensino da Botânica. Scientia cum Industria, 5 (3), 161167.

Lima, R. A., Pinto, M. N., Mendoza, A. Y. G., Silva, D. R., Nascimento, F. A., Rodrigues, J. J. P., Almeida, K. P. C., Vieira, R. L. \& Assis, S. N. S. (2019). A importância das plantas medicinais para a construção do conhecimento em botânica em uma escola pública no município de Benjamin Constant-amazonas (Brasil). Revista Ensino de Ciências e Humanidades Cidadania, Diversidade e Bem Estar, 2 (2), 478-492.

Lima, L. F. S. \& Oliveira, A. G. (2020). Etnobotânica e ensino: os estudantes do ensino fundamental como pesquisadores do conhecimento botânico local. Brazilian Journal of Development, 6 (7), 47766-47776.

Mera, J. C. E., Rosas, L. V., Lima, R. A. \& Pantoja, T. M. A. (2018). Conhecimento, percepção e ensino sobre plantas medicinais em duas escolas públicas no município de Benjamin Constant-AM. Experiências em Ensino de Ciências, 13 (2), p. 62-79.

Neri, G. F., Oliveira, T. L., Oliveira, V. J. S. \& Brito, N. M. (2018). Uso de Plantas Medicinais nas Unidades de Saúde da Família do Alto Sobradinho e Cocão do Município de Santo Antônio de Jesus-BA. Revista Ensaios Ciência, 22, 58-62.

Oliveira, D. L., Silva, N., Silva, F. S. \& Guimarães, A. S. (2020a). Integrando conhecimentos: uma abordagem etnobotânica para o ensino de ciências. Brazilian Journal of Development, 6 (9), 64202-64219.

Oliveira, V. M., Caldeira, A. J. R., Ayres, F. M. \& Santo, C. A. F. E. (2020b). Uso de plantas medicinais por idosos. Anápolis Digital, 10, 56-75.

Pio, I. D. S. L., Lavor, A. L., Damasceno, C. M. D., Menezes, P. M. N \& Silva, F. S. Maia, G. L. A. (2018). Traditional knowledge and uses of medicinal plants by the inhabitants of the islands of the São Francisco river, Brazil and preliminary analysis of Rhaphiodon echinus (Lamiaceae). Brazilian Journal of Biology, 79, 87-99.

Reis, C. R. M., Pereira, A. F. N \& Cansanção, I. F. (2017). Levantamento Etnobotânico de plantas medicinais utilizada por moradores do entorno do Parque Nacional Serra da Capivara-PI. Biofarm, 13 (4), 7-21.

Sales, M. D. C., Sartor, E. B \& Gentilli, R. M. L. (2015). Etnobotânica e etnofarmacologia: medicina tradicional e bioprospecção de fitoterápicos. Salus Journal of Health Sciences, 1, 17-26.

Santos, B. B. \& Campos, L. M. L. (2019). Plantas medicinais na escola: uma experiência com estudantes dos anos iniciais do Ensino Fundamental. Revista de Ensino de Ciências e Matemática, 10 (5), 271-290.

Santos, L. S. N., Salles, M. G. F., Pinto C. M., Pinto, O. R. O. \& Rodrigues, I. C. S. (2018). O saber etnobotânico sobre plantas medicinais na comunidade da Brenha, Redenção, CE. Agrarian Academy, 5 (9), 409-421.

Santos, R. E. \& Macedo, G. E. L. (2017). Aprendizagem significativa de conceitos botânicos em uma classe de jovens e adultos: análise dos conhecimentos prévios. Contexto \& Educação, 32 (101), 105-124.

Santos, T. A. X., Terra, F. M., Magaña, K. B. D., Silva, O. A. \& Damasceno, E. M. A. (2017). Conhecimento e uso de plantas medicinais por acadêmicos do curso de Farmácia. Visão Acadêmica, 20 (2), 17-28.

Santos, G. J. L. \& Pinheiro, D. C. S. N. (2016). Aspectos da terapia etnofarmacológica associados à atividade antitumoral. Revista Brasileira de Higiene e Sanidade Animal, 10 (3), 495-509.

SALESSE, D., MEDEIROS, F. C., Silva, C. C. M., Lourenço, E. L. B. \& Jacomassi, E. (2018). Etnobotânica e etnofarmacologia das espécies de Amaryllidaceae, Anacardiaceae, Annonaceae e Aapiaceae. Arquivos de Ciências da Saúde da UNIPAR, 22 (3), 199-204.

Silva, D. F. \& Santos, M. G. (2017). Plantas medicinais, conhecimento local e ensino de botânica: uma experiência no ensino fundamental. Revista Ciência \& Ideias, 8 (2), 140-164.

Madeiro, A. A. S. \& Lima, C. R. (2015). Estudos etnofarmacológicos de plantas medicinais utilizadas no Brasil: revisão de literatura. Ciências Biológicas e da Saúde, 3, 69-76.

Ursi, S., Barbosa, P.P., Sana, P. T \& Berchez, F. A. S. (2018). Ensino de botânica: conhecimento e encantamento na educação cientifica Estudos Avançados, $32(94), 7-24$.

Xavier, A. R., Sousa, L. M. \& Melo, J. L. M. (2019). Saberes tradicionais, Etnobotânica e o Ensino de Ciências: estudo em escolas públicas do Maciço de Baturité, Ceará, Brasil. Educação \& Formação, 4 (11), 215-233.

Zardo, A., Otenio, J. K.., Lourenço, E. L. B., Gasparotto Junior, A. \& Jacomassi, E. (2016). Levantamento de informações etnobotânicas, etnofarmacológicas e farmacológicas registradas na literatura sobre, Tropoeolum majus L. (Chaguinha). Arquivos de Ciências da Saúde da UNIPAR, 20 (3), 195-198.

Zeni, A. L. B., Parisotto, A. V., Mattos, G. \& Helena, E. T. S. (2017). Utilização de plantas medicinais como remédio caseiro na atenção primária em Blumenau, Santa Catarina, Brasil. Ciência \& Saúde Coletiva, 22 (8), 2703-2712. 
Research, Society and Development, v. 10, n. 4, e59510414484, 2021

(CC BY 4.0) | ISSN 2525-3409 | DOI: http://dx.doi.org/10.33448/rsd-v10i4.14484

Weyrich, L. S., Duchene, S., Soubrier, J., Arriola, L., Llamas, B., Breen, J \& Cooper, A. (2017). Neanderthal behaviour, diet, and disease inferred from ancient DNA in dental calculus. Nature, 544 (7650), 357-361.

Who. World Health Organization. (1992). International Statistical Classification of Diseases and Related Health Problems (ICD). https://www.who.int/standards/classifications/classification-of-diseases. 